\title{
Chapter 19 \\ Forecasting Life Expectancy and Mortality \\ in Sweden - Some Comments \\ on Methodological Problems and Potential Approaches
}

\author{
Måns Rosén
}

\subsection{Introduction}

Since mortality is affected by innumerable factors in society, an inter-disciplinary approach seems most appropriate. My contribution and point of departure starts from an epidemiological perspective and from the overall objective of the Swedish Centre for Epidemiology, i.e. to monitor public health in Sweden. ${ }^{1}$ An advantage of epidemiology is the close link to public health and medicine as well as its focus on analyses of risk factors and the search for causal chains between risk factors, diseases and mortality. Mortality forecasting is a well-established discipline in demography, but maybe less developed within epidemiology. Still, there have been attempts to forecast mortality within the field of epidemiology (see e.g. Wilhelmsen et al. 2004; Gunning-Schepers 1989; Gunning-Schepers et al. 1989; Kruijshaar et al. 2002; Conroy et al. 2003). Usually, epidemiologists have focused on estimating mortality for specific causes of death (Wilhelmsen et al. 2004; Conroy et al. 2003) but there are also attempts to predict total mortality (GunningSchepers 1989; Kruijshaar et al. 2002). A common application has been to predict coronary heart mortality based on data on risk factors, e.g. smoking, level of cholesterol and blood pressure in the population (Wilhelmsen et al. 2004; Conroy et al. 2003). Knowledge of risk factor patterns is therefore an essential element in epidemiology. The risk factor approach will be discussed later. First, some comments on the outline of this paper.

\footnotetext{
${ }^{1}$ National Board of Health and Welfare (2003).

M. Rosén (ه)

Centre for Epidemiology, National Board of Health and Welfare, Stockholm, Sweden

e-mail: mans.rosen@comhem.se 
I will start by introducing the two most widely used measures in epidemiology, i.e. incidence and prevalence, and the relationships between those two measures and mortality. Second, I will give some general comments on pros and cons with different options for mortality forecasting. The different options discussed are extrapolating mortality trends, predicting disease-specific causes of death, predicting mortality trends based on potential elimination of causes of death or predicting mortality based on risk factors or other developments in the community. Third, some methodological problems will be discussed. Finally, I will advocate a risk factor based approach and speculate about future mortality and longevity based on our attempts to monitor public health in Sweden.

\subsection{The Relationships Between Incidence, Prevalence and Mortality}

Incidence is defined as the number of new cases of a disease during a specified time period while prevalence is the total number of people with a disease at a specific point in time. It is well illustrated by a bath tube (Fig. 19.1) where the water coming through the tap is the incidence and the water in the bath tube is the prevalence. The prevalence is affected by the incidence, but also by the number of people cured or deceased.

Those who die will no longer belong to the population at risk while those who are cured still belong to the population at risk. The cured survivors will have a probability of contracting a new disease. Primary prevention may influence incidence while prevalence is more of a measure of the total disease burden for society.

Mortality is affected by the incidence, which could be divided into different components from demographic characteristics (number of people, population growth and changing age distribution) to the risk of having/attracting a disease (based on risk factor patterns). Mortality is also influenced by the chance of surviving a disease. All these components are important to consider in mortality forecasting.

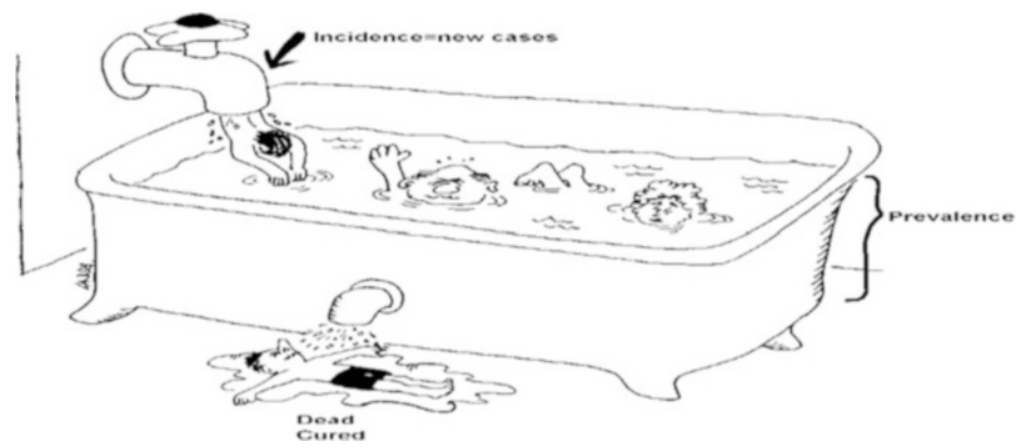

Fig. 19.1 The relationships between incidence, prevalence, mortality and cured 


\subsection{Extrapolating Mortality Trends or Predicting Disease- Specific Causes of Death}

Life expectancy has increased impressively during the past 150 years. In Sweden, life expectancy for a man has improved from 35 years in the beginning of the $1800 \mathrm{~s}$ to 61 years in the 1920 s and up to 77.91 years in 2003 . For women, life expectancy is 82.43 years in 2003 . This success story seems to be never ending. In the 1980s, many believed there was little potential for improvement, but they were wrong. Still, it seems unlikely and atheoretical to believe this can persist forever.

History can also show us the danger of only extrapolating existing trends. A recent and dramatic story is the development of mortality and life expectancy in Russia. ${ }^{2}$ Between 1970 and 1985 life expectancy in Russia was quite stable around 68 years (WHO). Between 1985 and 1987 it rose to 70 years followed by a substantial drop to about 64 years. Several studies have analysed the reasons to this dramatic and rapid change. The main explanations suggested are economic and social instability as well as changes in alcohol consumption (Shkolnikov et al. 2001; Notzon et al. 1998; Nemtsov 2002). The anti-alcohol campaign, launched in 1985, and the market reforms launched in 1992 were associated with large and rapid changes of alcohol consumption in Russia (Nemtsov 2002).

Trends in life expectancy among women in Denmark and the Netherlands can serve as other examples of the danger of only extrapolating trends. Since 1970, there is a steady increase in life expectancy for men both in Denmark and the Netherlands (WHO). However, extrapolating trends from the early 1970s would highly overestimate the longevity of women in Denmark and the Netherlands. Danish women increased their life expectancy substantially from about 76 years in 1970 to 78 years in 1977 followed by no increase at all up to 1995. After 1995 life expectancy among women in Denmark has started to increase again. For women in the Netherlands, life expectancy increased substantially up to 1990, but has thereafter not followed the increasing trends of many other western European countries. These changes in trends indicate clearly that the risk factor patterns of women in these two countries have been different than in other European countries.

The danger of extrapolating mortality trends is also evident when studying some disease-specific causes of death in Sweden. Lung cancer mortality among men increased substantially from the 1950s up to around the end of the 1970s followed by a decrease in both incidence and mortality (Fig. 19.2).

This trend break could easily have been anticipated if declining smoking rates had been considered. Smoking rates among men started to decline in the early $1960 \mathrm{~s}$ accompanied with a trend break for lung cancer about 20 years later. Smoking rates among women have increased up to the late 1970s followed by a small decrease in smoking rates. So far, no shift in lung cancer rates among women can be seen. However, lung cancer rates among women seem to be levelling off.

\footnotetext{
${ }^{2}$ WHO Europe Health for All database, see http://www.who.dk; Shkolnikov et al. (2001); Notzon et al. (1998); Nemtsov (2002).
} 


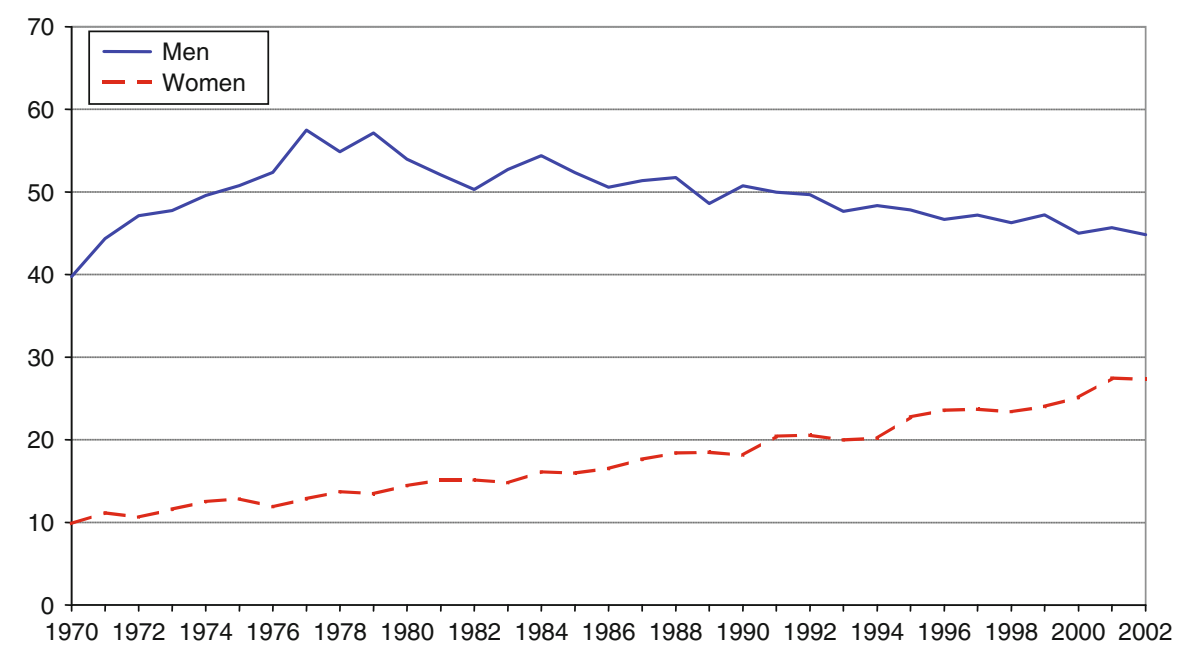

Fig. 19.2 Trends in lung cancer mortality in Sweden, 1970-2002

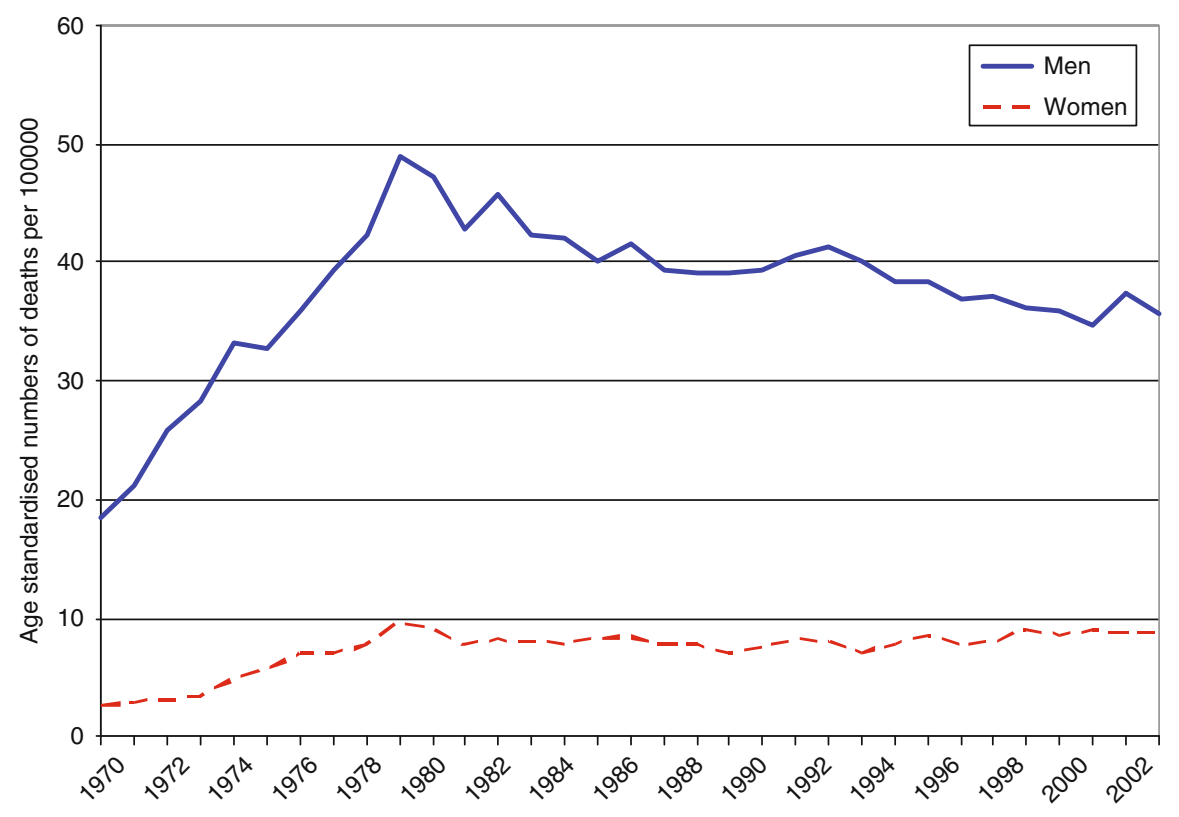

Fig. 19.3 Alcohol-related mortality in Sweden 1970-2002

Alcohol-related mortality rose dramatically after the abolishment of the Swedish rationing system in 1955 and it was first around 1980 a decreasing alcohol mortality trend was noticed (Fig. 19.3). This trend break was probably due to intensified efforts in society as a whole. Cohorts born in the 1960s and 1970s also seem to be very healthy cohorts with low smoking rates and moderate alcohol consumption. 


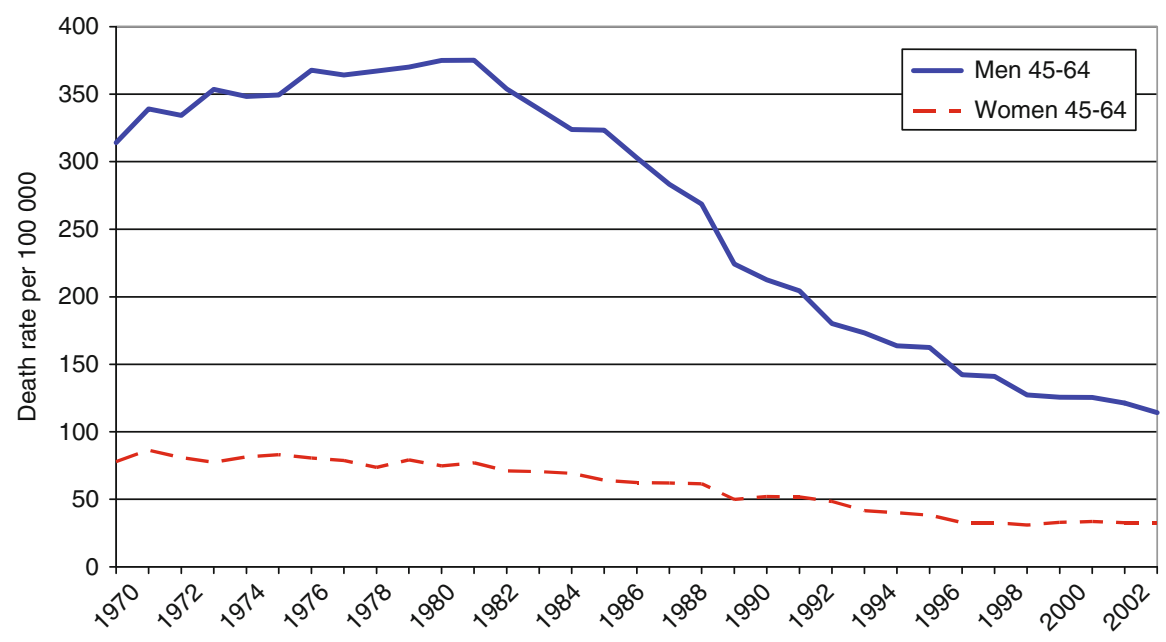

Fig. 19.4 Ischaemic heart disease mortality in Sweden 1970-2002, 45-64 years

The development of acute myocardial infarction and other coronary heart diseases among middle-aged men is another example of a trend break (Fig. 19.4). This trend break took place in the beginning of the 1980s and was due to several changes in risk factors, especially the decline in smoking rates among men. The level of serum cholesterol has also decreased in the Swedish population contributing to a decreasing trend in coronary heart mortality. All these examples clearly indicate caution in respect to merely extrapolating mortality trends.

\subsection{Predicting Mortality Based on Potential Elimination of Causes of Death}

To gain an idea of how great the potential is for increasing life expectancy one can do hypothetical calculations of how much it would increase if a disease no longer led to death (Curtin and Armstrong 1988; Haglund and Rosén 2001). In the Swedish Public Health Report of 2001 such calculations have been made (Haglund and Rosén 2001). The results are summarised in Table 19.1, which shows that the elimination of cardiovascular disease as a cause of death is the single most important step to prolong life expectancy followed by cancer. For cardiovascular disease more than 5 years could be gained for men by eliminating this disease group. Many may be surprised by the small gains obtained by eliminating traffic accidents ( 3 months for men and 1 month for women) or infectious diseases (1 month).

Social factors play an important role in the etiology of diseases and for mortality predictions. Upper white-collar workers have the lowest mortality. If the death risk for the whole population between 25 and 74 were reduced to the same level as for upper white-collar workers, men's life expectancy would have been 2 years and 
Table 19.1 Changes in life expectancy in months through elimination of certain diseases or risk factors in Sweden 1993-1997

\begin{tabular}{l|cc}
\hline Disease/risk factor & Men & Women \\
\hline Infections & 1 & 1 \\
Cancer & 34 & 37 \\
Cardiovascular diseases & 64 & 48 \\
Injuries and accidents & 12 & 6 \\
Traffic accidents & 3 & 1 \\
Tobacco & 16 & 8 \\
Social inequalities & 29 & 17 \\
\hline
\end{tabular}

Source: Haglund and Rosén (2001)

5 months longer and women's life expectancy 1 year and 5 months longer (Haglund and Rosén 2001).

\subsection{Predicting Mortality Based on Development of Risk Factors}

Predicting mortality based on social developments and predictions on risk factor changes seems most appropriate since these are the driving forces for mortality. The major problems are the lack of knowledge we have concerning all risk factors affecting all diseases. The three most important risk factors for coronary heart disease (CHD) are smoking, hypertension and high blood cholesterol levels. However, 247 risk factors for $\mathrm{CHD}$ have been suggested in the scientific literature (Hopkins and Williams 1981). It is impossible to make predictions for all these and many of them are not very well evidence based. Still, the three major risk factors explain quite a large proportion of CHD deaths and it is therefore much easier to predict the future CHD trends than to predict mortality for other causes of death, e.g. cancer where the knowledge base is more limited. Since about half of all deaths are caused by cardiovascular disease, it seems meaningful to make mortality predictions based on the risk factor development of this disease group.

\subsection{Methodological Problems in Predicting Mortality Based on Risk Factor Predictions}

In this paper I advocate a risk factor prediction approach to mortality forecasting. I hope the earlier presentation convincingly has shown the advantages of this approach in comparison with extrapolating mortality trends.

However, several methodological problems still exist. Four problems could be highlighted. Relative risks vary over time and by regions, latency times differ, co-morbidity and competing causes of death complicate the predictions and the lack of appropriate risk factor data limit the possibilities. 
In the case of coronary heart disease, longitudinal studies from different parts of the world have displayed the same major and independant risk factors, but with varying relative risks (Wilhelmsen et al. 2004; Conroy et al. 2003; Empana et al. 2003). The Framingham risk functions based on U.S. populations overestimate the absolute coronary heart disease risk of middle-aged men when they are applied to different European populations (Empana et al. 2003). A problem in estimating mortality trends is the long latency times between exposure to risk factors and when the individuals are strucked by the disease. For smoking and lung cancer latency time is usually more than 20 years of smoking. These kinds of considerations must be taken into account when making mortality predictions. However, the greatest problem in mortality modelling is usually lack of reliable risk factor data. Our own experiences of testing the Dutch mortality model (Gunning-Schepers 1989) on Swedish data showed the lack of risk factor data even in a data affluent society like Sweden.

\subsection{Future Mortality and Longevity}

As a simple exercise, Rosén and Haglund (2002) estimate future life expectancy in Sweden, not based on sophisticated dynamic population models, but merely on assumptions about risk factor developments and general knowledge about public health, recent successes in health care and the potential of eliminating certain causes of death (Table 19.2).

Social differences in mortality are large even in economically well-developed countries like Sweden. The reasons for these differences are multi-factorial and are most likely due to an accumulation of health risks during the whole life-cycle. Lower socio-economic groups have usually lower birth weights, have been brought up in more disadvantaged areas, have less education, smoke more, eat more unhealthy products, have more often monotonous work or are more often unemployed. However, history has shown that lower socio-economic groups will eventually reach the life expectancy of higher socio-economic groups, but that they are always 10-20 years behind. Eliminating the present social differences in health seems therefore a realistic scenario.

Table 19.2 Future estimated life expectancy (years) in Sweden

\begin{tabular}{l|l|l}
\hline Intervention & Men & Women \\
\hline Life expectancy, year 2000 & 77.4 & 82.0 \\
Eliminating social differences & +2.5 & +1.5 \\
Improved lifestyle & +1.5 & +1.5 \\
Improved medical care & +1.5 & +0.5 \\
Optimist supplement & +1.0 & +1.0 \\
\hline Estimated life expectancy & 84.0 & 87.0 \\
\hline
\end{tabular}

Source: Rosén and Haglund (2002) 
It is also obvious that eliminating cardiovascular disease has the greatest impact on longevity. This is an area where we have evidence based knowledge of risk factors and great potential for primary prevention. Since the 1990s medical technologies have had a success story in developing life-saving interventions in the field of coronary heart disease. Altogether, this implies a high potential for improving longevity by reducing mortality for cardiovascular disease. We estimated a gain of 1.5 years due to improved lifestyle, mainly reduced smoking rates, and further gains due to improved medical technologies of 1.5 years for men and 0.5 years for women. The larger estimated gain for men is due to the fact that medical interventions will influence cardiovascular disease most, which is a larger burden for men than women. Finally, we added an optimist supplement of 1 year for improvements not foreseen by our estimates.

\subsection{Implications for the Future}

Mortality forecasting plays an important role for development and maintenance of national and private insurance schemes. However, there are also other social and economic consequences of changing mortality trends. A lively discussion has been whether prolonging lives may lead to compression or expansion of morbidity (Thorslund et al. 2004). Many studies in the past have indicated decreasing morbidity and improved functional status among the elderly, i.e. supporting the hypothesis of compression of morbidity. Recent studies in Sweden show, however, deteriorating health in some aspects among the elderly (Thorslund et al. 2004; Rosén and Haglund 2005). This development supports the hypothesis that we now are going from healthy survivors to sick survivors due to improvement in health care (Rosén and Haglund 2005). Since the late 1980s, new and very effective life-saving drugs and treatments have been developed, especially in the field of cardiovascular disease. This has had tremendous effect on survival among patients with acute myocardial infarction, heart failure and diabetes. Those surviving will, however, live with their chronic diseases and demand more care than earlier "healthy" survivors.

\section{References}

Conroy, R. M., Pyörälä, K., Fitzgerald, A. P., Sans, S., Menotti, G., De Bacquer, D., et al. (2003). Estimation of ten-year risk of fatal cardiovascular disease in Europe: The SCORE project. European Heart Journal, 24, 987-1003.

Curtin L. R., \& Armstrong, R. J. (1988). "United States life tables eliminating certain cases of death. U.S. decennial life tables for 1979-81.” Vol 1, No 2. DHHS Pub. No (PHS) 88-1150-2, Public Health Service. Washington, DC: U.S. Government Printing Office.

Empana, J. P., Ducemetiere, P., Arveiler, D., et al. (2003). Are the Framingham and PROCAM coronary heart disease risk functions applicable to different European populations? The PRIME study. European Heart Journal, 24, 1903-1911. 
Gunning-Schepers, L. (1989). The health benefits of prevention: Simulation approach. Health Policy, 12, 1-255.

Gunning-Schepers, L., Barendregt, J. J., \& Van Der Maas, P. J. (1989). Population interventions reassessed. Lancet, 1, 479-481.

Haglund, B., \& Rosén, M. (2001). Public health in the future. Scandinavian Journal of Public Health, 58, 231-239.

Hopkins, P. N., \& Williams, R. R. (1981). A survey of 246 suggested risk factors. Atherosclerosis, $40,1-52$.

Kruijshaar, M. E., Barendregt, J. J., \& Hoeymans, N. (2002). The use of models in the estimation of diease epidemiology. Bulletin World Health Organisation, 80, 622-628.

National Board of Health and Welfare. (2003). A finger on the pulse. Monitoring public health and social conditions in Sweden 1992-2002. Stockholm: Centre for Epidemiology, National Board of Health and Welfare.

Nemtsov, A. V. (2002). Alcohol-related human losses in Russia in the 1980s and 1990s. Addiction, 97, 1413-1425.

Notzon, F. C., Komarov, Y. M., Ermakov, S. P., Sempos, C. T., Marks, J. S., \& Sempos, E. V. (1998). Causes of declining life expectancy in Russia. JAMA, 279, 793-800.

Rosén, M., \& Haglund, B. (2002). Hur länge kommer vi att leva? Framtider, 1, 16-19.

Rosén, M., \& Haglund, B. (2005). From healthy survivors to sick survivors - Implications for the twenty-first century. Scandinavian Journal of Public Health, 33(2), 151-155.

Shkolnikov, V., McKee, M., \& Leon, D. A. (2001). Changes in life expectancy in Russia in the mid-1990s. Lancet, 357, 917-921.

Thorslund, M., Lennartsson, C., Parker, M. G., \& Lundberg, O. (2004). De allra äldstas hälsa har blivit sämre. Könsskillnaderna är stora - kvinnorna mår sämre visar nya data. Läkartidningen, 101, 1494-1499.

WHO Europe Health-for-All-Database., see http://www.who.dk

Wilhelmsen, L., Lappas, G., \& Rosengren, A. (2004). Risk of coronary events by baseline factors during 28 years follow-up and three periods in a random population sample of men. Journal of Internal Medicine, 256, 298-307.

Open Access This chapter is licensed under the terms of the Creative Commons Attribution 4.0 International License (http://creativecommons.org/licenses/by/4.0/), which permits use, sharing, adaptation, distribution and reproduction in any medium or format, as long as you give appropriate credit to the original author(s) and the source, provide a link to the Creative Commons license and indicate if changes were made.

The images or other third party material in this chapter are included in the chapter's Creative Commons license, unless indicated otherwise in a credit line to the material. If material is not included in the chapter's Creative Commons license and your intended use is not permitted by statutory regulation or exceeds the permitted use, you will need to obtain permission directly from the copyright holder. 